\title{
Corrigendum: Exploring judgement and internal bias of Life Orientation teachers in sexuality teaching
}

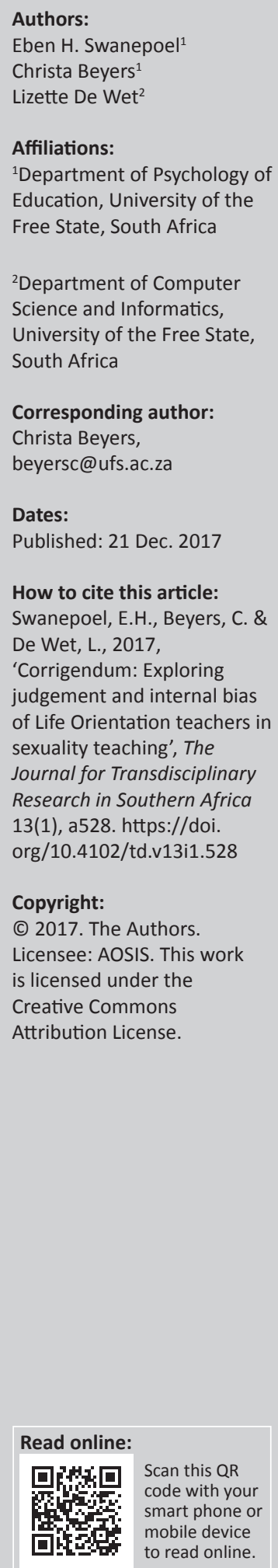

Scan this QR

In the version of this article initially published, a reference was misrepresented in the reference list. The reference is hereby corrected to:

Francis, D., 2017, Troubling the teaching and learning of gender and sexuality diversity in South African Education, Palgrave Macmillan, New York.

The errors have been corrected in the PDF version of the article. The author apologises for any inconvenience that this may have caused. 